\title{
Hydrothermal Processing of Phase Pure and Doped Hydroxyapatite and its Characterization
}

\author{
Muhammad Musaddique Ali Rafique \\ ${ }^{1}$ Department of Metallurgical and Materials Engineering, University of Engineering and Technology, Lahore, Pakistan \\ ${ }^{2}$ Interdisciplinary Research Centre in Biomedical Materials (IRCBM), COMSATS Institute of Information Technology, Lahore, \\ Pakistan \\ Email: ali.rafique@hotmail.com
}

How to cite this paper: Rafique, M.M.A. (2018) Hydrothermal Processing of Phase Pure and Doped Hydroxyapatite and its Characterization. Journal of Encapsulation and Adsorption Sciences, 8, 18-37. https://doi.org/10.4236/jeas.2018.81002

Received: December 14, 2017

Accepted: March 26, 2018

Published: March 30, 2018

Copyright $\odot 2018$ by author and Scientific Research Publishing Inc. This work is licensed under the Creative Commons Attribution International License (CC BY 4.0).

http://creativecommons.org/licenses/by/4.0/

\begin{abstract}
Hydroxyapatite (HA) is a synthetic ceramic which is used in numerous biomedical applications. However, its use is restricted in load bearing applications. A novel batch hydrothermal method is indigenously developed to synthesize fine size, crystalline hydroxyapatite (HA) and titania doped hydroxyapatite $\left(\mathrm{TiO}_{2}-\mathrm{HA}\right)$ powders with distinct phase formation. Powders were characterized using XRD, FTIR and DSC-TGA. Sharp peaks in HA XRD pattern after sintering at $1000^{\circ} \mathrm{C}$ indicate significant crystallinity while sharp peaks in $\mathrm{TiO}_{2} \mathrm{XRD}$ pattern at $27^{\circ}, 36^{\circ}$ and $5^{\circ}$ after sintering indicate anatase to rutile transformation. This fact is also confirmed by FTIR and DSC-TGA Plots.
\end{abstract}

\section{Keywords}

Hydrothermal, Hydroxyapatite, XRD, FTIR, DSC-TGA

\section{Introduction}

Hydroxyapatite (HA) is an important synthetic biomaterial owing to its similarity to naturally occurring biological apatite found in the organs of living organisms. It is the major constituent of inorganic component of human hard tissues, bone, teeth and tendon, which is responsible for the stability, hardness and function of these organs. Majority of calcium phosphates are remarkably biocompatible and bioactive. This property is increasingly important in medicine and dentistry [1]. However, it is soft in its nature which limits its application to non-load bearing parts and segments only. It cannot sustain large constant and impact loads and undergoes deformation which causes them to lose their shape. 
For example, in a study by Ashok and co-workers [1], it is shown that hydroxyapatite only stays intact and maintains their integrity under normal operating conditions. As the loading is increased and becomes critical, fine hydroxyapatite crystals starts disintegrating and finally deteriorate resulting in de shaping of internal and external structure of organ or wound. This may be illustrated by another example, in which synthetic hydroxyapatite crystals were compacted and sintered to make pellets which are subjected to indentation hardness [2]. Again, they do not exhibit consistency in their behaviour with the application of load like metals or alloys. Under the effect of indenter, they tend to show complete structural disintegration and no visible or remarkable indent shape is observed. This property, however, is a strong function of applied load and sintering conditions and its effect varies from case to case. Doping is a technique which is attributed to countering this effect and contributes towards increase of hardness of synthetic hydroxyapatite [3] [4] [5] [6]. Classically, HA powders and coatings can be synthesised using several methods including sol-gel processing [7], wet chemistry and co-precipitation [8], emulsion techniques, microwave synthesis [9], batch hydrothermal processes [1] [2] [10] [11] [12] [13], mechano-chemical methods, sono-chemical methods and chemical vapour deposition. The disadvantages of these methods include: Imprecise control over reaction conditions, expensive starting materials or large amounts of toxic organic solvents, expensive tooling, and/or prolonged reaction time. Furthermore, the aforementioned synthesis approaches give little or no control over HA particle characteristics (i.e. particle size, its distribution, agglomeration surface area, morphology and shape) [2]. These drawbacks could be overcome by adopting to certain modifications in hydrothermal process which is one of the oldest techniques used to develop different forms of crystalline material(s) [13]. In biomaterials development, it has gained recent attention due to its ability to produce nanosize crystals, time and energy efficiency, low temperatures and hence low processing cost [12]. Disadvantages include high initial cost and inability to go to high temperatures to achieve high productivity by speeding up of the process due to inner liner (TEFLON) limitation. Recently, hydroxyapatite [1] [2] [10] [11] and titania [14] [15] [16] [17] [18] powders are produced by hydrolysis [15] [17] or hydrothermal techniques [15] [16] [18] employing homogeneous and heterogeneous type reactions using different precursors and/or starting materials (e.g. isopropoxide with [16] or without [14] [17] acetic acid). In titania, two distinct phases occur namely Rutile and Anatase. Rutile is always used as a source of light scattering but anatase is used as photo catalyst and photo-electron transfer medium [17]. Results showed that hydrothermal processing saves a lot of time and energy and is environment friendly to produce very fine size pure (phase pure) and mixed hydroxyapatite and titania (mixture of anatase and rutile) powders. In present study, above mentioned bottlenecks are removed, and inherent advantages are utilised by employing a novel batch hydrothermal reactor which gives higher yield, higher throughput and versatility in control of 
reaction conditions by manipulation of temperature and pressure not attempted previously. This results in improved and enhanced product quality. Carefully selected calcium and ammonium precursors of salts and hydroxides are used as starting material for the synthesis of hydroxyapatite under strong basic conditions followed by hydrothermal treatment at $130^{\circ} \mathrm{C}$ for $6 \mathrm{hrs}$ and organic oxide of titanium along with acid-base reflux is used as starting material for the synthesis of titania under strong basic conditions. The phase, structure, composition and morphology are studied by $x$-ray diffraction (XRD), Fourier transform infrared spectroscopy (FTIR), and differential scanning calorimetry (DSC) - thermos-gravimetric analysis (TGA) analysis techniques.

\section{Materials and Methods}

Hydroxyapatite nano powder (phase pure), phase pure titania and homogeneously and heterogeneously titania mixed (doped) hydroxyapatite are synthesized by hydrothermal route. Calcium Nitrate $\left(\mathrm{Ca}\left(\mathrm{NO}_{3}\right)_{2} \cdot 4 \mathrm{H}_{2} \mathrm{O}\right), \geq 99.0 \%$, Fluka Chemie, Switzerland), di-ammonium hydrogen phosphate $\left(\left(\mathrm{NH}_{4}\right)_{2} \mathrm{HPO}_{4}\right)$ Assay $99 \%-102 \%$, Sigma Aldrich Inc. USA) and ammonium hydroxide $\left(\mathrm{NH}_{4} \mathrm{OH}, 5.0\right.$ $\mathrm{N}$, Sigma Aldrich Inc, USA) were used as starting material. Also, titanium dioxide micro powder is synthesized by hydrothermal route. titanium propoxide $\left(\mathrm{Ti}\left(\mathrm{OC}_{3} \mathrm{H}_{7}\right)_{4}\right), 98 \%$, Fluka Chemie, Switzerland), ammonium hydroxide $\left(\mathrm{NH}_{4} \mathrm{OH}, 5.0 \mathrm{~N}\right.$, Sigma Aldrich Inc, USA) and nitric acid $\left(\mathrm{HNO}_{3}, 65 \%\right.$ Merck, Germany) were used as starting materials. Same chemicals are also used for homogeneous reactions. Calculated amount of calcium nitrate (Table 1) is first

Table 1. Calculations: Hydrothermal synthesis of hydroxyapatite and titania (heterogeneous and homogeneous reactions).

\begin{tabular}{|c|c|c|c|c|c|}
\hline Sr. No. & Chemical & Moles & Wt $(g)$ & Vol. (ml) & Volume water $(\mathrm{ml})$ \\
\hline \multicolumn{6}{|c|}{ Hydroxyapatite synthesis } \\
\hline 1 & $\mathrm{Ca}\left(\mathrm{NO}_{3}\right)_{2} \cdot 4 \mathrm{H}_{2} \mathrm{O}$ & 1 & 59.04 & & 250 \\
\hline 2 & $\left(\mathrm{NH}_{4}\right)_{2} \mathrm{HPO}_{4}$ & 0.6 & 19.82 & & 250 \\
\hline 3 & $\mathrm{NH}_{4} \mathrm{OH}$ & & & 320 & \\
\hline \multicolumn{6}{|c|}{ Hydroxyapatite and titania (homogeneous synthesis) } \\
\hline 5 & $\mathrm{Ca}\left(\mathrm{NO}_{3}\right)_{2} \cdot 4 \mathrm{H}_{2} \mathrm{O}$ & 1 & 59.04 & & 250 \\
\hline 6 & $\left(\mathrm{NH}_{4}\right)_{2} \mathrm{HPO}_{4}$ & 0.6 & 19.82 & & 250 \\
\hline 7 & $\mathrm{Ti}\left(\mathrm{OC}_{3} \mathrm{H}_{7}\right)_{4}$ & & & 4.70 & \\
\hline 8 & $\mathrm{NH}_{4} \mathrm{OH}$ & & & 378.22 & \\
\hline \multicolumn{6}{|c|}{ Hydroxyapatite and titania (heterogeneous synthesis) } \\
\hline 10 & $\mathrm{Ca}\left(\mathrm{NO}_{3}\right)_{2} \cdot 4 \mathrm{H}_{2} \mathrm{O}$ & 1 & 59.04 & & 250 \\
\hline 11 & $\left(\mathrm{NH}_{4}\right)_{2} \mathrm{HPO}_{4}$ & 0.6 & 19.82 & & 250 \\
\hline 12 & $\mathrm{TiO}_{2}$ & & 1.32 & & \\
\hline 13 & $\mathrm{NH}_{4} \mathrm{OH}$ & & & 378.22 & \\
\hline
\end{tabular}


dissolved in water and di-ammonium hydrogen phosphate is added in it drop wise (40 drops/min) $(\sim 1.4 \mathrm{ml} / \mathrm{sec})$ using $250 \mathrm{ml}$ dropping funnel. Immediate precipitation starts. $\mathrm{pH}$ of solution is maintained at $\sim 11$ and not allowed to go below 10 by continuous time dependent addition of $\mathrm{NH}_{4} \mathrm{OH}$ (hydroxyapatite formation).

For homogeneous precipitation, calculated amount of titanium isopropoxide (TPO) $\left(\mathrm{Ti}\left(\mathrm{OC}_{3} \mathrm{H}_{7}\right)_{4}\right)$ (Table 1) is first mixed with calcium nitrate under the action of rigorous stirring and di-ammonium hydrogen phosphate is added in it drop wise (40 drops/min) ( 1.4 ml/sec) using $250 \mathrm{ml}$ dropping funnel. Immediate precipitation starts. $\mathrm{pH}$ of solution is maintained at $\sim 11$ and not allowed to go below 10 by continuous time dependent addition of $\mathrm{NH}_{4} \mathrm{OH}$. For heterogeneous precipitation, first phase pure titania is synthesized. This is done by addition of $\mathrm{NH}_{4} \mathrm{OH}$ solution to $\left(\mathrm{Ti}\left(\mathrm{OC}_{3} \mathrm{H}_{7}\right)_{4}\right)$ in an ice bath to form titanic acid $\left(\mathrm{Ti}(\mathrm{OH})_{4}\right)$ and then dissolved with $\mathrm{HNO} 3$ to form titanyl nitrate $\left(\mathrm{TiO}\left(\mathrm{NO}_{3}\right)_{2}\right)$. $\mathrm{HNO}_{3}$ was added until the $\mathrm{pH}$ of final solution becomes 1 . This is washed with excess water to separate out titania which is then dried. Final titania crystals are scraped out from filter paper. Calculated amount of these titania $\left(\mathrm{TiO}_{2}\right)$ crystals (Table 1) is mixed with calcium nitrate with constant stirring by using inert TEFLON stirrer. di-ammonium hydrogen phosphate is added in it drop wise (40 drops/min) $(\sim 1.4 \mathrm{ml} / \mathrm{sec})$ using $250 \mathrm{ml}$ dropping funnel. Immediate precipitation starts. $\mathrm{pH}$ of solution is maintained at $\sim 11$ and not allowed to go below 10 by continuous time dependent addition of $\mathrm{NH}_{4} \mathrm{OH}$. All three above mixtures are poured into hydrothermal vessel one after the other and treated at $130^{\circ} \mathrm{C}$ for 6 hrs. Final solutions are filtered and dried in an Oven (Diahan Scientific Co., Korea) at $80^{\circ} \mathrm{C}$ for $24 \mathrm{hrs}$ to form final products. Hydrothermal vessel used for conducting reactions is shown schematically in below figure (Figure $1(\mathrm{~A})$ and Figure 1(B)) to illustrate its manufacture and construction. The significance of this device is that it was first of its kind in Pakistan used for production of hydroxyapatite and other reactive oxides at large scale. Vessel has the capacity to produce $1 \mathrm{Kg}$ hydroxyapatite in one batch. Process has higher efficiency, is environment friendly and easy to control. Very fine crystals are produced which can be further tailored to the meet requirement of application.

Flow chats describing synthesis and processing of all three materials are shown in Figures 2(A)-(C) below. They describe in detail the step by step production of hydroxyapatite, homogeneously precipitated hydroxyapatite and titania (co precipitated) and heterogeneously precipitated hydroxyapatite and titania (seeded growth).

The phases were studied by an X-ray diffractometer (BRUKER D8-Advanced, USA at Department of Chemistry, Quaid-e-Azam University, Islamabad, Pakistan) (step size 0.02 , scan Rate $2 \mathrm{o} / \mathrm{s}$, voltage $40 \mathrm{KV}$, radiation $\mathrm{Cu} \mathrm{Ka}$ ). (Figure 3(A) \& (Figure 3(B)). Infrared spectroscopic analysis of nanopowder was done using Nicolet 6700 FT-IR Thermo Fisher, USA Instrument at IRCBM, COMSATS Institute of information technology, Lahore, Pakistan (Resolution $8 \mathrm{~cm}^{-1}$, Scan 


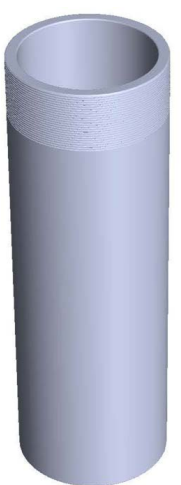

(A)

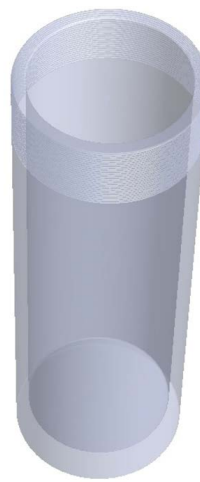

(B)

Figure 1. (A) Hydrothermal stainless-steel vessel (outside view); (B) schematic inside view.

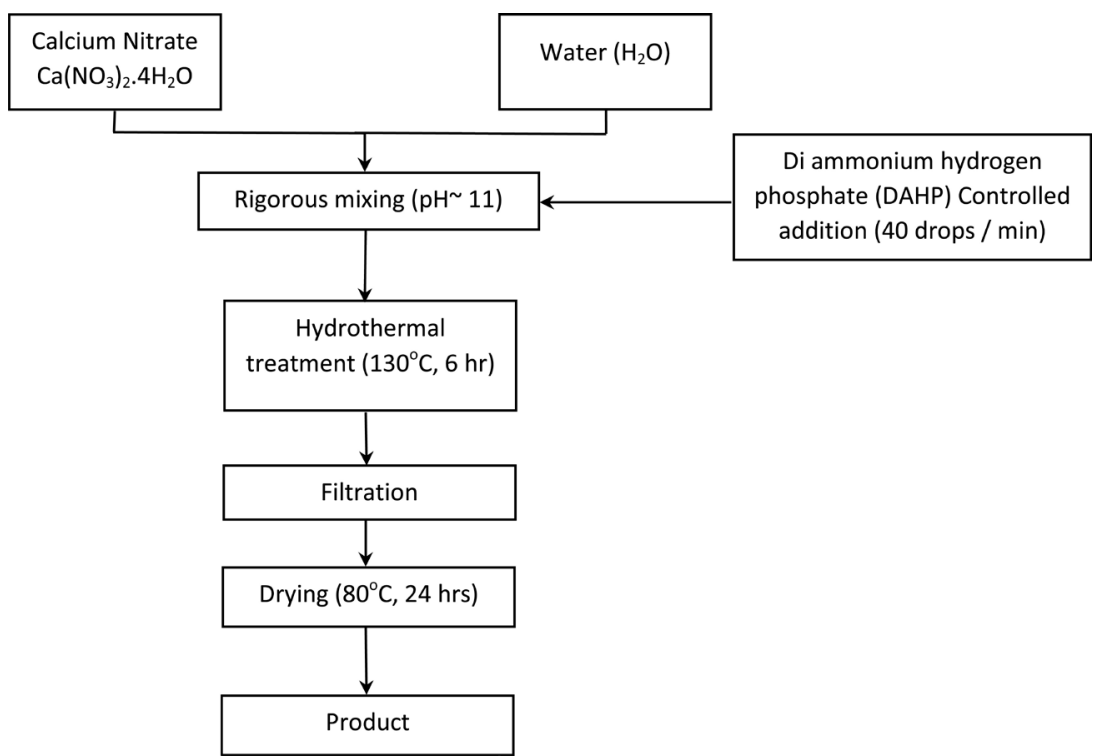

(A)

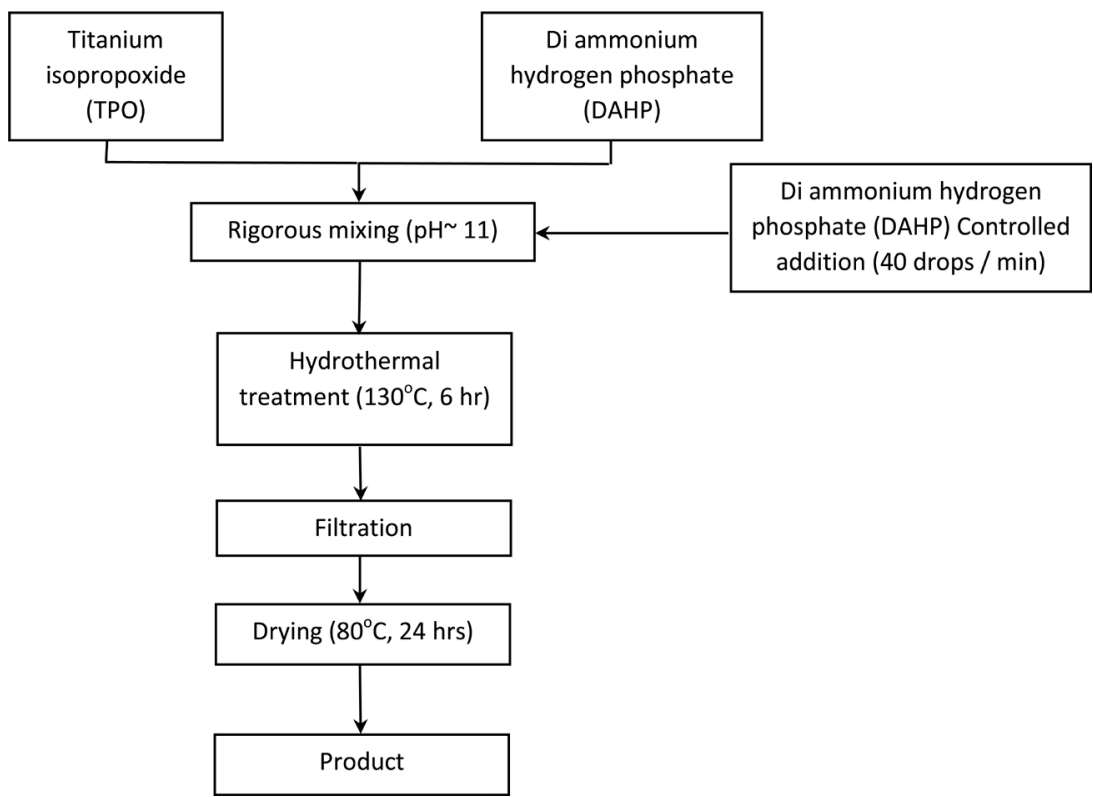

(B) 


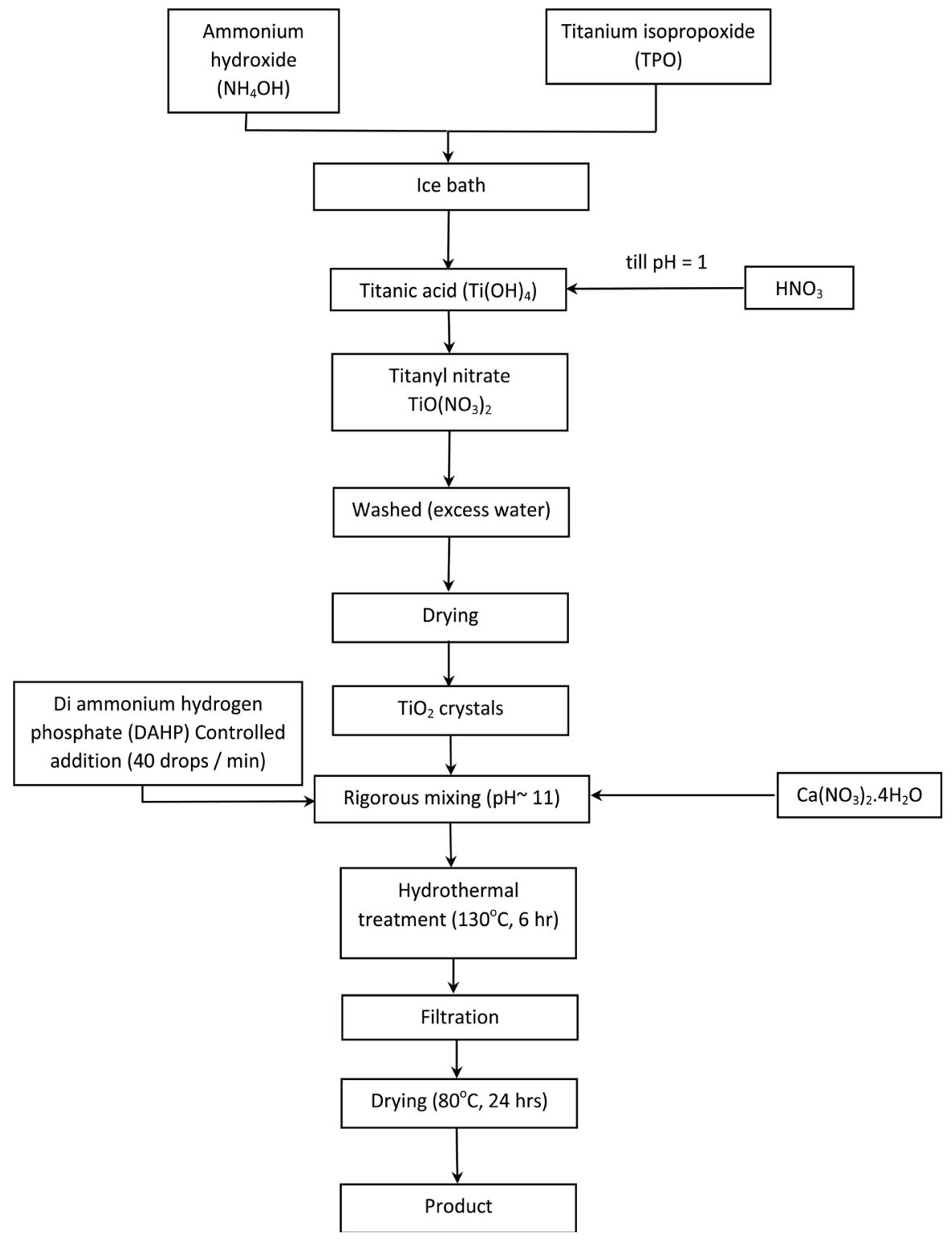

(C)

Figure 2. (A) Flow chart describing batch hydrothermal processing of phase pure hydroxyapatite; (B) Flow chart describing batch hydrothermal processing of homogeneously precipitated hydroxyapatite doped with titania (HA and titania co precipitated); (C) Flow chart describing batch hydrothermal processing of heterogeneously precipitated hydroxyapatite doped with titania (HA grown on titania seeds);

time 256, Region $500-4000 \mathrm{~cm}^{-1}$ ) (Figure 4(A) \& (Figure 4(B)). DSC and TGA analysis was done using SDT (DSC-TGA Q 600 TA, USA Instrument at IRCBM, COMSATS Institute of information technology, Lahore, Pakistan (heating rate $10^{\circ} \mathrm{C} / \mathrm{min}$, heating temperature $1200^{\circ} \mathrm{C}$ ) (Figures $5(\mathrm{~A})-(\mathrm{h})$ ).

\section{Results and Discussion}

1) $X$-Ray Diffraction $(X R D)$

XRD pattern of hydroxyapatite (phase pure), Titania (phase pure), Hy- 
droxyapatite and titania (homogeneous precipitation) and Hydroxyapatite, titania (heterogeneous precipitation) as precipitated and heat treated $1000^{\circ} \mathrm{C}, 1 \mathrm{hr}$ are shown in Figure 3(A) \& Figure 3(B) respectively. They are identified as HAp (Figure 3(A) \& Figure 3(B)-(a)) [19] [20]. All peaks correspond to hexagonal crystal system of HAp [21]. Meanwhile, the high purity of HA phase was confirmed by XRD patterns. However, it is shown that the diffraction peaks of HAp in pattern ((B) (a)) are much stronger than pattern ((A) (a)) indicating that the crystallinity of the HAp nanoparticles heat treated after processing is much higher than "as precipitated" also XRD patterns of the powders treated for $6 \mathrm{hrs}$ show peaks attributed only to HAp, indicating the absence of monetite $\left(\mathrm{CaHPO}_{4}\right)$ [10].

Figure 3(A) \& Figure 3(B)-(b) shows the $\mathrm{XRD}$ pattern of $\mathrm{TiO}_{2}$ nanopowder

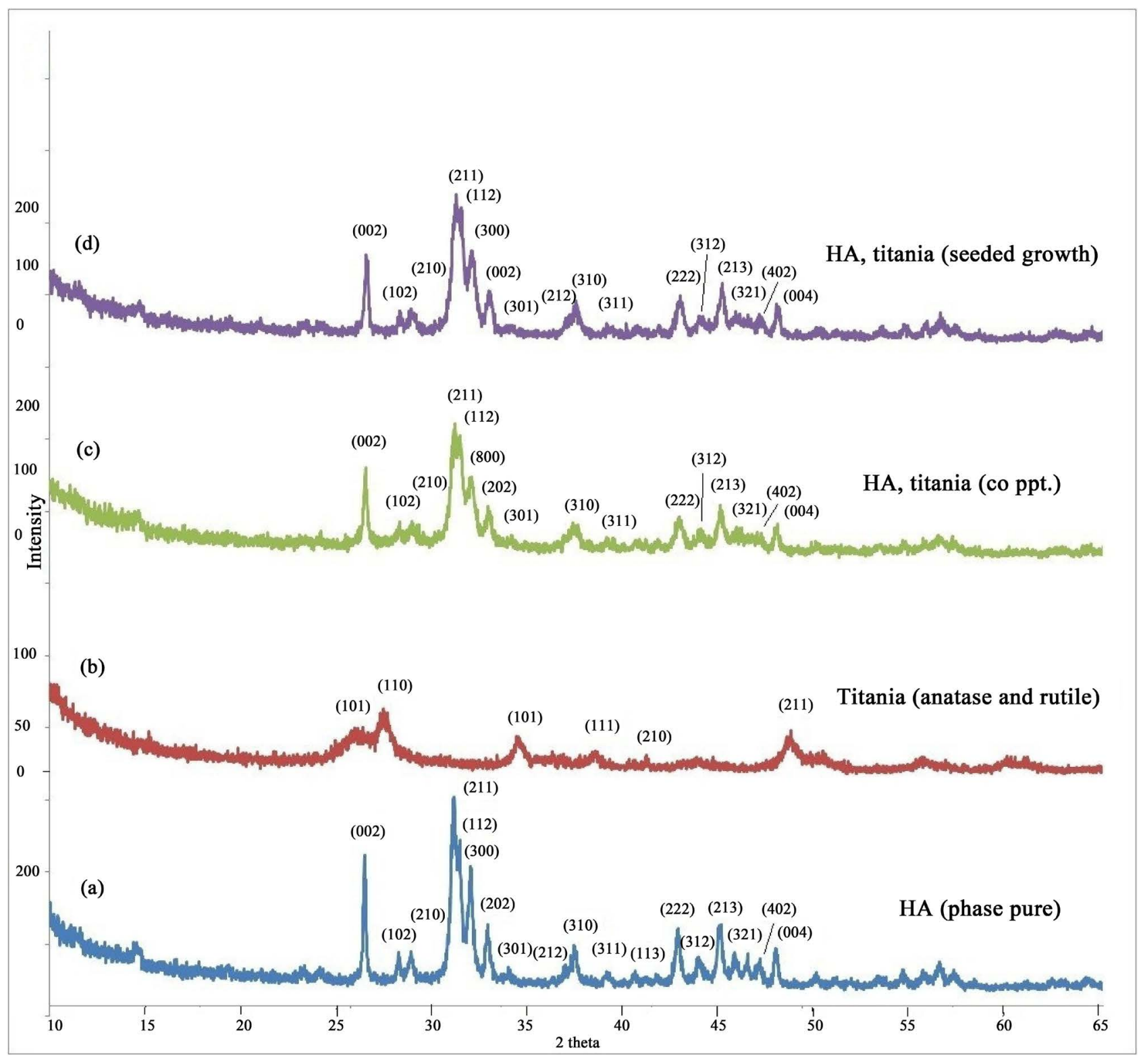

(A) 


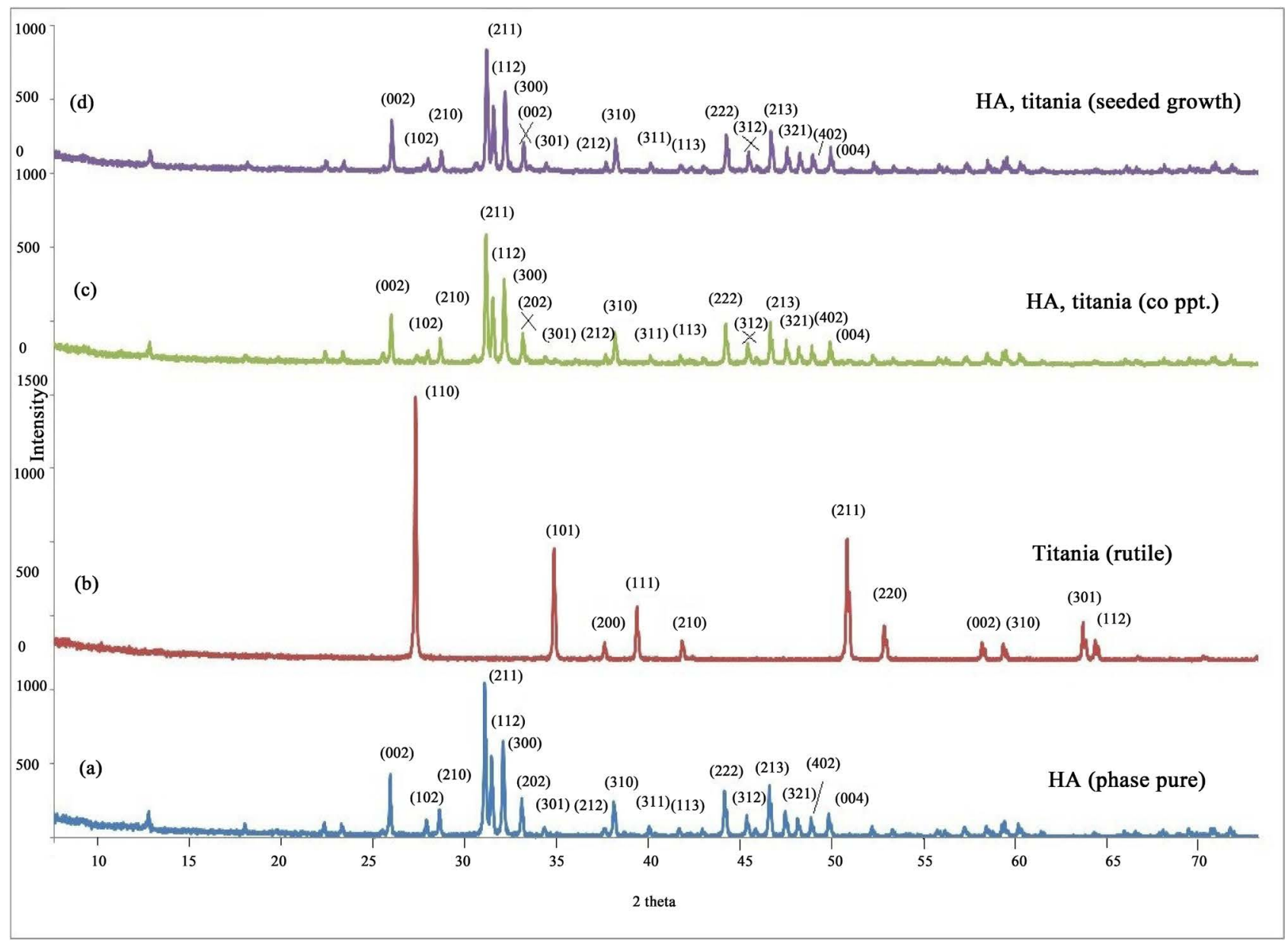

(B)

Figure 3. (A) XRD pattern of as precipitated hydroxyapatite (phase pure) (a), as precipitated titania (b), HA and titania (co precipitated (homogeneous precipitation)) (c), and HA and titania (seeded growth (heterogeneous precipitation)) (d) hydrothermal treated, dried $80^{\circ} \mathrm{C}$ for $24 \mathrm{hrs}$. (B) XRD pattern of heat treated hydroxyapatite (phase pure) (a), as precipitated titania (b), HA and titania (co precipitated (homogeneous precipitation)) (c), and HA and titania (seeded growth (heterogeneous precipitation)) (d) Hydrothermal treated, dried $80^{\circ} \mathrm{C}$ for $24 \mathrm{hrs}$, heat treated $1000^{\circ} \mathrm{C}$ for $1 \mathrm{hr}$.

synthesized by hydrothermal route treated at $130^{\circ} \mathrm{C}$ for $6 \mathrm{hrs}$ and dried at $80^{\circ} \mathrm{C}$ for $24 \mathrm{hrs}$ (Figure $3(\mathrm{~A})-(\mathrm{b})$ ), treated at $130^{\circ} \mathrm{C}$ for $6 \mathrm{hrs}$, dried at $80^{\circ} \mathrm{C}$ for $24 \mathrm{hr}$ and heat treated $1000^{\circ} \mathrm{C}$ for $1 \mathrm{hr}$ (Figure 3(B)-(b)). At $130^{\circ} \mathrm{C}$ for $6 \mathrm{hrs}$ and dried at $80^{\circ} \mathrm{C}$ for $24 \mathrm{hrs}$ multiphase of anatase and rutile structure of $\mathrm{TiO}_{2}$ nanopowder were obtained [22]. Pattern exhibited strong diffraction peaks at $26^{\circ}, 27^{\circ}$, $36^{\circ}, 49^{\circ}$ and $54^{\circ}$ indicating $\mathrm{TiO}_{2}$ in the anatase and rutile phase [23] while at $130^{\circ} \mathrm{C}$ for $6 \mathrm{hrs}$, dried $80^{\circ} \mathrm{C}$ for $24 \mathrm{hrs}$ and heat treated $1000^{\circ} \mathrm{C}$ for $1 \mathrm{hr}$ pattern exhibited strong diffraction peaks at $27^{\circ}, 36^{\circ}$ and $54^{\circ}$ indicating $\mathrm{TiO}_{2}$ in the form of rutile phase [23]. The temperature and holding time of hydrothermal process was lower than the previously reported values [24]. The noise in the pattern is due to large step size and less step time, the wideness is due to nanosized [25]. From Figure 3(A) \& Figure 3(B)-(b), it was shown that the diffraction pattern peak intensity of the $\mathrm{TiO}_{2}$ increases with increasing particles size. These results suggested that the nano- $\mathrm{TiO}_{2}$ powder is composed of irregular polycrystals. 
Amorphous structure revealed a broad pattern with low intensity; however, the effect of the amorphous materials on the broadening of the XRD patterns of nanosized $\mathrm{TiO}_{2}$ is negligible [23].

Figure 3(A) \& Figure 3(B)-(c) shows the $\mathrm{XRD}$ pattern of $\mathrm{TiO}_{2}$ and hydroxyapatite nanopowder co precipitated (homogeneous precipitation) by hydrothermal route while keeping the operating parameter same as for standalone hydroxyapatite and titania processing. At $130^{\circ} \mathrm{C}$ for $6 \mathrm{hrs}$ and dried at $80^{\circ} \mathrm{C}$ for $24 \mathrm{hrs}$ pattern is typical of hydroxyapatite [19] [20], however it is not that distinct as Figure 3(A)-(a) above and this deviation from distinct pattern is attributed to the presence of small amount of titania (anatase) though there is no sharp evidence/peak of it at given experimental conditions which is confirmed later on (Figure 3(B)-(c)). Same powder treated thermally at $1000^{\circ} \mathrm{C}$ for 1 hour shows sharp peaks of titania (rutile) along with hydroxyapatite indicating successful doping (Figure 3(B)-(c)). Pattern exhibited strong diffraction peaks at $34^{\circ}$ and $48^{\circ}$ indicating $\mathrm{TiO}_{2}$ in the form of rutile phase [26]. Further analysis of pattern exhibits absence of TCP indicating formation of phase pure hydroxyapatite [27].

Figure 3(A) \& Figure 3(B)-(d) shows the XRD pattern of $\mathrm{TiO}_{2}$ and hydroxyapatite nanopowder (seeded growth (heterogeneous precipitation)) synthesized by hydrothermal route while keeping the operating parameter same as for standalone hydroxyapatite and titania processing. At $130^{\circ} \mathrm{C}$ for $6 \mathrm{hrs}$ and dried at $80^{\circ} \mathrm{C}$ for $24 \mathrm{hrs}$ pattern is typical of hydroxyapatite [19] [20]. Titania, though present in the composition, does not shows up in the pattern, is due to the fact percentage of titania is too low as well as powder is in as precipitated condition. Pattern also differs from standard phase pure hydroxyapatite pattern [19] [20] (i.e. shows peak broadening and intensity change) due to aforementioned reasons. Same powder treated thermally at $1000^{\circ} \mathrm{C}$ for 1 hour shows sharp peaks of titania (rutile) along with hydroxyapatite indicating successful doping (seeded growth of hydroxyapatite on already existing titania (precursor) nanoparticles) (Figure 3(B)-(d)). Pattern exhibited strong diffraction peaks at $34^{\circ}$ and $48^{\circ}$ indicating $\mathrm{TiO}_{2}$ in the form of rutile phase [26].

From thermodynamics and kinetics stand point [9], undercooling is suppressed while kinetics is promoted during hydroxyapatite synthesis and processing, Undercooling is suppressed by continuous time dependent supply of heat from reaction itself (autogenous reaction), and from external heating elements. This combination of heating does not allow solution to go to a subzero temperature or at a temperature below crystallization temperature. Thus, no undercooling occurs at all. This also promotes proper crystallisation as it gives ample time to solution to allow second phase to precipitate out from it due to difference in solubility/immiscibility. On the other hand, kinetics is promoted as again there is enough time available for solute to come out of solution along with existence of a thermal gradient. These both factors contribute towards triggering of nucleation and growth events and their promotion. Proper crystallisation occurs which is a distinct and significant feature of this process for hydroxyapatite syn- 
thesis. This may be explained more elaborately by the help of a cooling curve.

2) Fourier Transform Infrared (FTIR) Spectroscopy

FTIR Spectra of hydroxyapatite (phase pure), Titania (phase pure), Hydroxyapatite and titania (co precipitated (homogeneous precipitation)) and Hydroxyapatite, titania (seeded growth (heterogeneous precipitation)) as precipitated and heat treated at $1000^{\circ} \mathrm{C}, 1 \mathrm{hr}$ are shown in Figure 4(A) \& Figure 4(B) respectively.

\section{i) Hydroxyapatite}

The wave numbers for characteristic peaks in both spectra are a function of heat treating temperature and changes with degree of heat treatment given which helped in removal of unwanted constituents and/or formation of new phases [28].

- Bands at 3572,631 , and $342 \mathrm{~cm}^{-1}$ are assigned to stretching mode ( $v$ s), librational mode $(v \mathrm{~L})$, and translational mode $(v \mathrm{~T})$, respectively, of the hydroxyl group, $\mathrm{OH}$ [8] [29]. The peak at 342, which is followed by another weak at $355 \mathrm{~cm}^{-1}$ (known as shoulder peak), is assigned to the hydroxyl group oscillating vertically to the crystallographic $c$-axis approaching and going away from the neighbouring plane defined by the three calcium ions, $\mathrm{Ca}^{2+}[30]$.

- Bands at 1087, 1072 - 1032, 962, 601, 571, and $474 \mathrm{~cm}^{-1}$ are assigned to vibrations of the phosphate group, $\mathrm{PO}_{4}$. The first peak at $1087 \mathrm{~cm}^{-1}$ emanates from a triply degenerated asymmetric stretching mode vibration, $v_{3}$ [8] [31]. The other two components of this triply degenerated vibration $\left(v_{3}\right)$ of the $\mathrm{P}-\mathrm{O}$ bond of the phosphate group appear at 1046 and $1032 \mathrm{~cm}^{-1}$. The peak at 962 $\mathrm{cm}^{-1}$ is assigned to a nondegenerated symmetric stretching mode $\left(v_{1}\right)$ of the $\mathrm{P}-\mathrm{O}$ bond of the phosphate group, $\mathrm{PO}_{4}[30]$. The peaks at 601, 575, and 561 $\mathrm{cm}^{-1}$ are assigned to a triply degenerated bending mode $\left(v_{4}\right)$ of the $\mathrm{O}-\mathrm{P}-\mathrm{O}$ bond [30]. The weak peaks at 472 and the shoulder at $462 \mathrm{~cm}^{-1}$ are components of the doubly degenerated bending mode, $\left(v_{2}\right)$ of the phosphate group, $\mathrm{PO}_{4}$ [30] [32].

- The peak at $2000 \mathrm{~cm}^{-1}$ is assigned to a $2 v_{3}$ harmonic overtone or to a combination mode $v_{1}+v_{3}[16]$.

- The peak at $361 \mathrm{~cm} \mathrm{~cm}^{-1}$ is a combination mode from the difference $v_{1}-v_{4}$ [30].

- The peaks at 2070 and $1154 \mathrm{~cm}^{-1}$ have been interpreted as combination bands or harmonic overtones [33].

This information is summarized in Table 2. The changes in the heat-treated sample was verified from the absence of peaks, which might be due to the removal of volatile constituents and/or transformation of low temperature phase(s) to high temperature phase(s) [34] [35] [36].

ii) Titania

Characteristic peaks for N-H stretch appear at $3382.27 \mathrm{~cm}^{-1}$ (S-A) \& 3393.37 $\mathrm{cm}^{-1}$ (S-B) [35]. A peak at 3498.77 (S-A) \& at 3149.92 (S-B) occurs due to O-H stretch. Peak at wave number of 2911.70 (S-A) \& 2908.58 (S-B) is due to C-H 


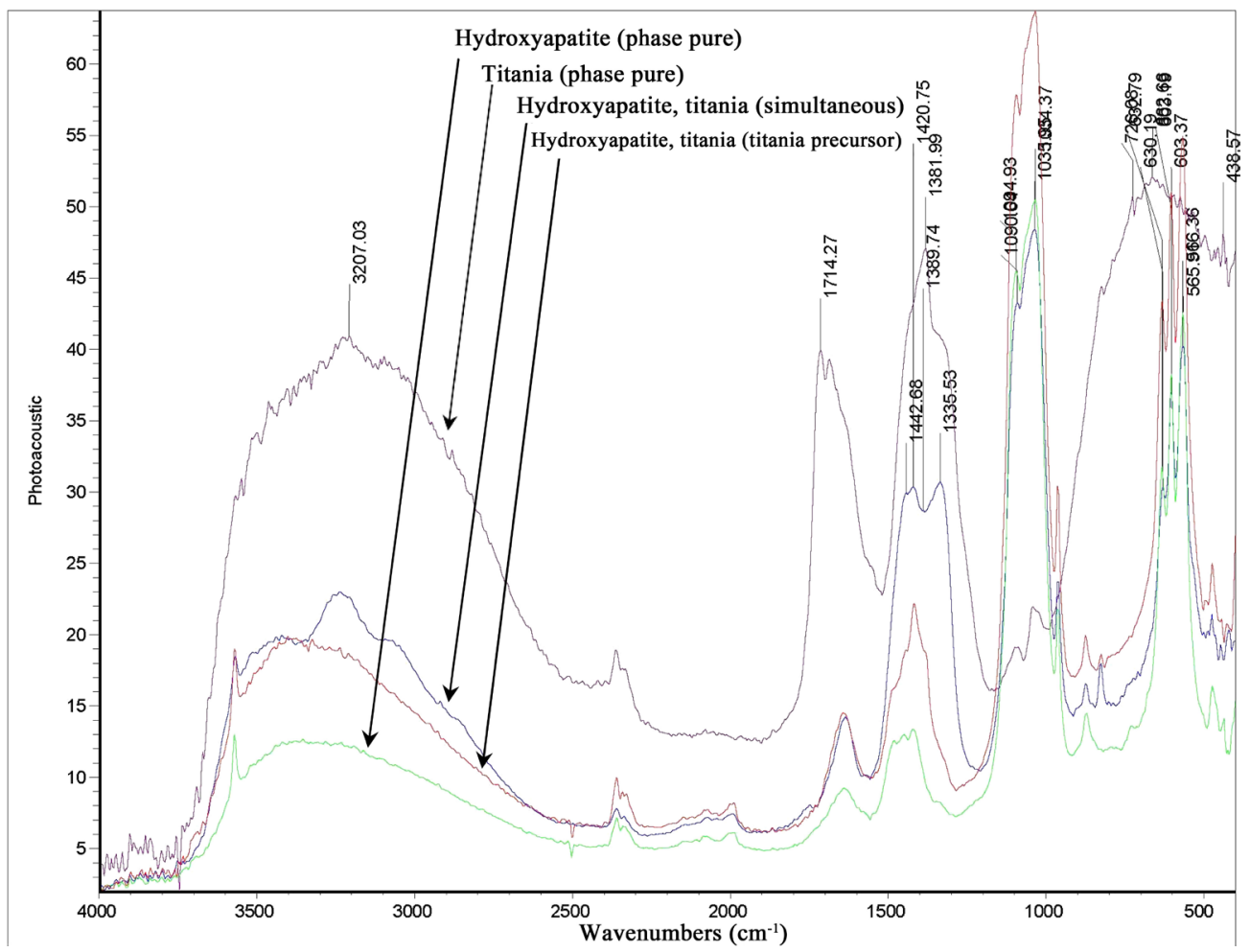

(A)

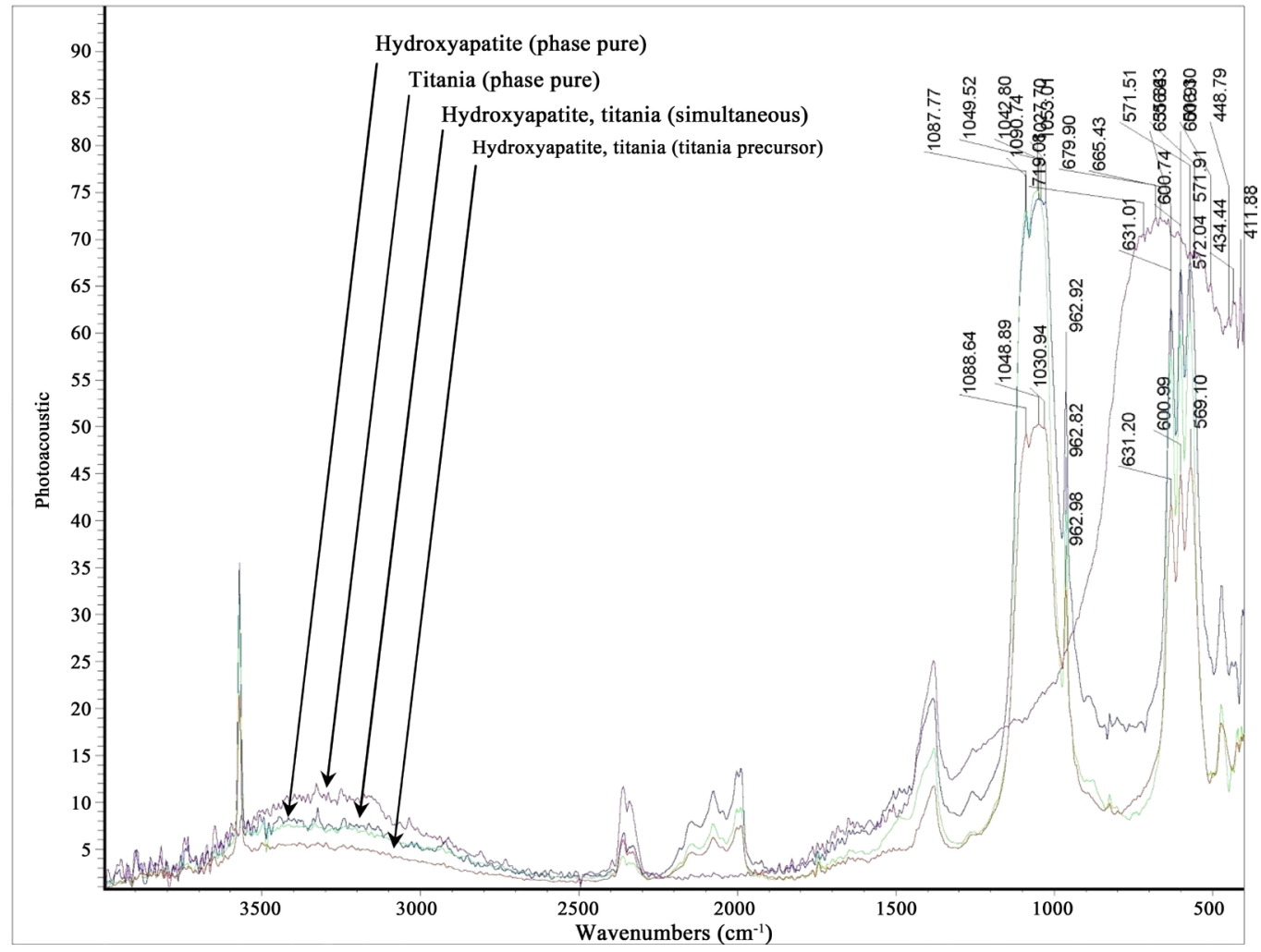

(B)

Figure 4. (A) FTIR Spectra of as precipitated hydroxyapatite (phase pure), Titania (phase pure), Hydroxyapatite and titania (simultaneously processed) and Hydroxyapatite, titania (titania precursor); (B) FTIR Spectra of heat treated $1000^{\circ} \mathrm{C}, 1 \mathrm{hr}$ hydroxyapatite (phase pure), Titania (phase pure), Hydroxyapatite and titania (co precipitated) and Hydroxyapatite, titania (seeded growth) 
Table 2. Infrared absorption spectroscopy for HAP; bands and assignments.

\begin{tabular}{|c|c|c|}
\hline Peak $\left(\mathrm{cm}^{-1}\right)$ & Assignment & Reference \\
\hline $3572(\mathrm{w})$ & Stretching mode, $v$ s, of the hydroxyl group & [37] [38] [39] \\
\hline $2070(\mathrm{w})$ & Harmonic overtone or combination band & [33] \\
\hline $2000(w)$ & Harmonic overtone $2, v_{3}$ or combination band $v_{1}+v_{3 \mathrm{~b}}$ & {$[30][33][40]$} \\
\hline $1154(w)$ & Harmonic overtone or combination band & [33] \\
\hline $1087(\mathrm{~s})$ & Triply degenerated asymmetric stretching mode $\left(v_{3 \mathrm{a}}\right)$ of the $\mathrm{P}-\mathrm{O}$ bond of the phosphate group & [31] [32] \\
\hline $1046(\mathrm{~s})$ & Triply degenerated asymmetric stretching mode $\left(v_{3 \mathrm{~b}}\right)$ of the $\mathrm{P}-\mathrm{O}$ bond of the phosphate group & [30] \\
\hline $1032(\mathrm{sh})$ & Triply degenerated asymmetric stretching mode $\left(v_{3 c}\right)$ of the $\mathrm{P}-\mathrm{O}$ bond of the phosphate group & {$[30][31][40]$} \\
\hline $962(w)$ & Nondegenerated symmetric stretching mode $\left(v_{1}\right)$ of the $\mathrm{P}-\mathrm{O}$ bonds of the phosphate group & [30] [31] [32] [33] \\
\hline $631(\mathrm{~m})$ & Librational mode $(\nu \mathrm{L})$ of the hydroxyl group & [8] [29] \\
\hline $602(s, \operatorname{shp})$ & Triply degenerated bending mode $\left(v_{4 a}\right)$ of the $\mathrm{O}-\mathrm{P}-\mathrm{O}$ bonds of the phosphate group & {$[30][31][40]$} \\
\hline $574(\mathrm{~s}, \mathrm{sh})$ & Triply degenerated bending mode $\left(v_{4 \mathrm{~b}}\right)$ of the $\mathrm{O}-\mathrm{P}-\mathrm{O}$ bonds of the phosphate group & {$[30][32][40]$} \\
\hline $561(\mathrm{~s})$ & Triply degenerated bending mode $\left(v_{4 c}\right)$ of the $\mathrm{O}-\mathrm{P}-\mathrm{O}$ bonds of the phosphate group & {$[30][32][40]$} \\
\hline $472(w)$ & Double degenerated bending mode $\left(v_{2 \mathrm{a}}\right)$ of the $\mathrm{O}-\mathrm{P}-\mathrm{O}$ bonds of the phosphate group & [30] [32] \\
\hline $462(w, s h)$ & Double degenerated bending mode $\left(v_{2 \mathrm{~b}}\right)$ of the $\mathrm{O}-\mathrm{P}-\mathrm{O}$ bonds of the phosphate group & [30] [32] \\
\hline $361(w, s h)$ & HAP lattice vibration mode or combination band $\left(v_{1}-v_{4}\right)$ & [30] [33] \\
\hline $355(\mathrm{sh})$ & Translational mode $(v \mathrm{~T})$ of the hydroxyl group $\left(v_{3}\right)$ & [30] \\
\hline $342(\mathrm{w}, \mathrm{sh})$ & Translational mode $(v \mathrm{~T})$ of the hydroxyl group $\left(v_{3}\right)$ & [8] [29] [30] \\
\hline
\end{tabular}

w: weak, m: medium, s: strong, sh: shoulder, shp: sharp.

stretch. Peak at wave number of 2364.50 (S-A) \& 2361.67 (S-B) is due to C (triple bond) $\mathrm{N}$ stretch in nitriles. Peak at wave number of 2109.48 (S-A) \& 2117.26 (S-B) is due to $\mathrm{C}$ (triple bond) $\mathrm{C}$ stretch in alkynes. Peaks at wave number of 1685.42 \& 1716.96 (S-A) \& $1696.79 \& 1716.66$ (S-B) is due to $\mathrm{C}=\mathrm{O}$ stretch in carbonyl (general) groups. Large domb (peak) on the left of spectra (Figure $4(\mathrm{~A})$ ) is may be due Unreacted species in reactants which are causing abnormalities [34] and adsorbed OH groups on the surface of titania [35] [36] which is not removed upon drying of materials at such low temperatures. This however, is removed at higher temperature heat treatment.

iii) Hydroxyapatite, titania (co precipitated (homogeneous precipitation))

The wave numbers for characteristic peaks in both spectra are a function of heat treatment temperature in this case also and changes with degree of heat treatment given, removing of unwanted constituents and/or formation of new phases [28].

- Bands at 3572,631 , and $342 \mathrm{~cm}^{-1}$ are assigned to stretching mode ( $v$ s), librational mode $(v \mathrm{~L})$, and translational mode $(v \mathrm{~T})$, respectively, of the hydroxyl group, $\mathrm{OH}$ [8] [29]. The peak at 342, which is followed by another weak at $355 \mathrm{~cm}^{-1}$ (shoulder), is assigned to the hydroxyl group oscillating vertically to the crystallographic c-axis approaching and going away from the neighbouring plane defined by the three calcium ions, $\mathrm{Ca}^{2+}[30]$. 
- Bands at 1087, $1072-1032,962,601,571$, and $474 \mathrm{~cm}^{-1}$ are assigned to vibrations of the phosphate group, $\mathrm{PO}_{4}$. The first peak at $1087 \mathrm{~cm}^{-1}$ emanates from a triply degenerated asymmetric stretching mode vibration, $v_{3}[8]$ [31]. The other two components of this triply degenerated vibration, $v_{3}$, of the $\mathrm{P}-\mathrm{O}$ bond of the phosphate group appear at 1046 and $1032 \mathrm{~cm}^{-1}$. The peak at 962 $\mathrm{cm}^{-1}$ is assigned to a nondegenerated symmetric stretching mode, $v_{1}$, of the $\mathrm{P}-\mathrm{O}$ bond of the phosphate group, $\mathrm{PO}_{4}[30]$. The peaks at 601,575 , and 561 $\mathrm{cm}^{-1}$ are assigned to a triply degenerated bending mode, $v_{4}$, of the $\mathrm{O}-\mathrm{P}-\mathrm{O}$ bond [30]. The weak peaks at 472 and the shoulder at $462 \mathrm{~cm}^{-1}$ are components of the doubly degenerated bending mode, $v_{2}$, of the phosphate group, $\mathrm{PO}_{4}[30]$ [32]

- The peak at $2000 \mathrm{~cm}^{-1}$ is assigned to a $2 v_{3}$ harmonic overtone or to a combination mode, $v_{1}+v_{3}[30]$.

- The peak at $361 \mathrm{~cm}^{-1}$ is a combination mode from the difference $v_{1}-v_{4}$ [30].

- The peaks at 2070 and $1154 \mathrm{~cm}^{-1}$ have been interpreted as combination bands or harmonic overtones [33].

iv) Hydroxyapatite, titania (seeded growth (heterogeneous precipitation))

The wave numbers for characteristic peaks in both spectra also depend on heat treatment temperature and alters with extent of heat treatment given which helped in removal of unwanted constituents and/or formation of new phases as occur in earlier formulations [28].

- Bands at 3572,631 , and $342 \mathrm{~cm}^{-1}$ are assigned to stretching mode (vs), librational mode $(v \mathrm{~L})$, and translational mode $(v \mathrm{~T})$, respectively, of the hydroxyl group, OH [8] [29]. The peak at 342, which is followed by another weak at $355 \mathrm{~cm}^{-1}$ (shoulder), is assigned to the hydroxyl group oscillating vertically to the crystallographic c-axis approaching and going away from the neighbouring plane defined by the three calcium ions, $\mathrm{Ca}^{2+}[30]$.

- Bands at 1087, 1072 - 1032, 962, 601, 571, and $474 \mathrm{~cm}^{-1}$ are assigned to vibrations of the phosphate group, $\mathrm{PO}_{4}$. The first peak at $1087 \mathrm{~cm}^{-1}$ emanates from a triply degenerated asymmetric stretching mode vibration, $v_{3}[8]$ [31]. The other two components of this triply degenerated vibration, $v_{3}$, of the $\mathrm{P}-\mathrm{O}$ bond of the phosphate group appear at 1046 and $1032 \mathrm{~cm}^{-1}$. The peak at 962 $\mathrm{cm}^{-1}$ is assigned to a nondegenerated symmetric stretching mode, $v_{1}$, of the $\mathrm{P}-\mathrm{O}$ bond of the phosphate group, $\mathrm{PO} 4$ [30]. The peaks at 601, 575, and 561 $\mathrm{cm}^{-1}$ are assigned to a triply degenerated bending mode, $v_{4}$, of the $\mathrm{O}-\mathrm{P}-\mathrm{O}$ bond [30]. The weak peaks at 472 and the shoulder at $462 \mathrm{~cm}^{-1}$ are components of the doubly degenerated bending mode, $v_{2}$, of the phosphate group, $\mathrm{PO}_{4}[30]$ [32].

- The peak at $2000 \mathrm{~cm}^{-1}$ is assigned to a $2 v_{3}$ harmonic overtone or to a combination mode, $v_{1}+v_{3}[30]$.

- The peak at $361 \mathrm{~cm}^{-1}$ is a combination mode from the difference $v_{1}-v_{4}$ [30].

- The peaks at 2070 and $1154 \mathrm{~cm}^{-1}$ have been interpreted as combination bands or harmonic overtones [33]. 
c) Differential scanning calorimetry and thermo-gravimetric analysis (DSC-TGA)

i) Hydroxyapatite (phase pure)

The thermogram of the synthesized material shows three distinct stages of decomposition (Figure 5(A)). The first stage that occurs between $35^{\circ} \mathrm{C}$ and $120^{\circ} \mathrm{C}$ is due to loss of adsorbed water. The major weight loss that occurs between $150^{\circ} \mathrm{C}$ and $260^{\circ} \mathrm{C}$ is assigned to the decomposition of agarose and ammonium. The dehydration of $\mathrm{Ca}(\mathrm{OH})_{2}$ into $\mathrm{CaO}$ also contributes to a part of this weight loss and the total weight loss in this second stage is $9.55 \%$. The third weight loss that occurs between $260^{\circ} \mathrm{C}$ and $380^{\circ} \mathrm{C}$ is due to the decomposition of nitrate. This temperature range for nitrate decomposition was also reported previously [7]. DSC analysis (heating) (Figure 4(B)) shows a large broad peak demonstrated by HA powder, which is labelled from around $1200^{\circ} \mathrm{C}$ to $1340^{\circ} \mathrm{C}$ (extrapolated). It suggests the dehydration of $\mathrm{HA}$ over a wide temperature range and phase transformation of HA to oxyhydroxyapatite (OHAP, $\mathrm{Ca}_{10}\left(\mathrm{PO}_{4}\right)_{6}(\mathrm{OH})_{2-\mathrm{x}} \mathrm{O}_{\mathrm{x}}$ ) [41] [42]. In order to further reveal the thermal behaviour of the samples at elevated temperatures. DSC cooling curves was also studied, which are demonstrated in Figure 5(B). It is found that, for pure HA, only one visible peak appears, which is around $1440^{\circ} \mathrm{C}$ (not shown), and it may refer to the reversed full phase transformation from unstable a-TCP to $\alpha$-TCP [42]. The a-TCP may come from the transformation of $\alpha$-TCP at elevated temperatures [42]. Owing to lack of water in the pure nitrogen atmosphere, no peaks referring to reversible transformation from TCP or TTCP to oxyapatite or HA are present, which was revealed by other researchers using air circumstance [41].

ii) Titania

TGA of the samples was carried out in the range ambient $-1200^{\circ} \mathrm{C}$ at heating rate of $10^{\circ} \mathrm{C}$ minute in a nitrogen atmosphere [25] (Figure 5(C)). Prior to each run, the empty sample pan was completely tared to get accurate balance. The final weight loss is about $26.34 \%$. Below $100^{\circ} \mathrm{C}$, the weight loss is attributed to the loss of adsorbed water on the surface of the powder. The second rage of weight lost ranges from $100^{\circ} \mathrm{C}-550^{\circ} \mathrm{C}$, is attributed to the decomposition of volatile organic solvents [14] [43]. The DSC curve (Figure 5(D)) showed a sharp endothermic peak around $100^{\circ} \mathrm{C}$, which was followed by a broad exothermic peak. The broad peak changed to a plateau shape around $520^{\circ} \mathrm{C}$, and continued until around $800^{\circ} \mathrm{C}$ [44], indicating no considerable change in titania over a temperature range.

\section{iii) Hydroxyapatite, titania (co precipitated (homogeneous precipitation))}

The thermogram of the synthesized material is more similar to that for titania, deviating from standard titania curve (Figure $5(\mathrm{C})$ ), indicating the presence of hydroxyapatite as well (Figure $5(\mathrm{E})$ ). It shows that below $100^{\circ} \mathrm{C}$, the weight loss is attributed to the loss of adsorbed water on the surface of the powder. The second rage of weight lost ranges from $100^{\circ} \mathrm{C}-550^{\circ} \mathrm{C}$, is attributed to the decomposition of volatile organic solvents [29] [30]. The final weight loss is about $23.81 \%$. The DSC curve (Figure $5(\mathrm{~F})$ ) also deviates from standard curve for titania 

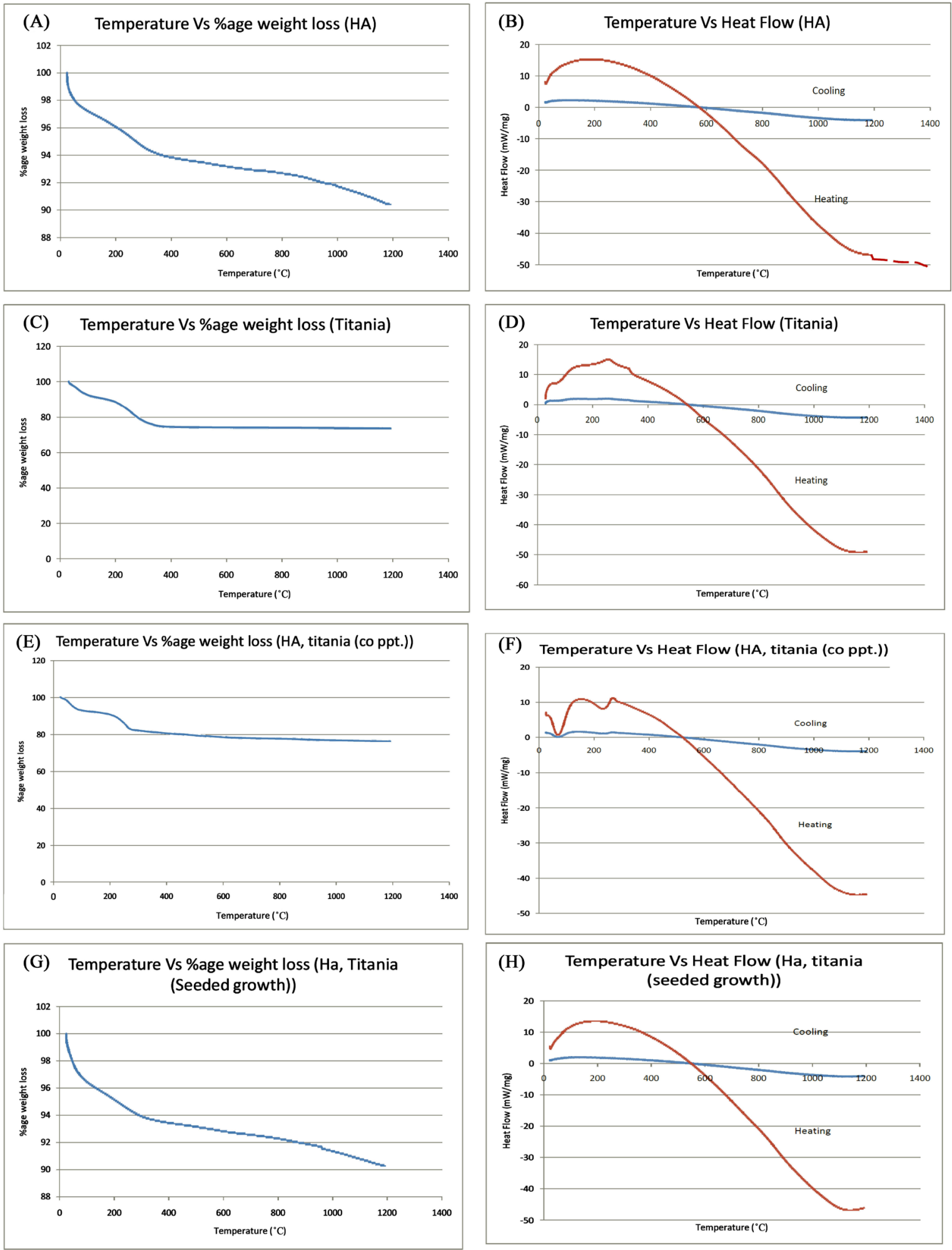

Figure 5. (A) TGA Analysis of hydroxyapatite (phase pure) hydrothermal treated, dried $80^{\circ} \mathrm{C}$ for 24 hrs. (B) DSC scan of hydroxyapatite (phase pure) hydrothermal treated, dried $80^{\circ} \mathrm{C}$ for $24 \mathrm{hrs}$, (C) TGA Analysis of titania, hydrothermal treated, dried $80^{\circ} \mathrm{C}$ for $24 \mathrm{hrs}$, (D) DSC scan of titania, hydrothermal treated, dried $80^{\circ} \mathrm{C}$ for $24 \mathrm{hrs,} \mathrm{(E)} \mathrm{TGA} \mathrm{Analysis} \mathrm{of} \mathrm{HA,} \mathrm{titania} \mathrm{(co} \mathrm{pre-}$ cipitated), hydrothermal treated, dried $80^{\circ} \mathrm{C}$ for $24 \mathrm{hrs,} \mathrm{(F)} \mathrm{DSC} \mathrm{scan} \mathrm{of} \mathrm{HA,} \mathrm{titania} \mathrm{(co} \mathrm{precipitated),} \mathrm{hydrothermal} \mathrm{treated,} \mathrm{dried}$ $80^{\circ} \mathrm{C}$ for $24 \mathrm{hrs}(\mathrm{G}) \mathrm{TGA}$ Analysis of HA, titania (seeded growth), hydrothermal treated, dried $80^{\circ} \mathrm{C}$ for $24 \mathrm{hrs,}$, $\mathrm{H}$ ) DSC scan of $\mathrm{HA}$, titania (seeded growth), hydrothermal treated, dried $80^{\circ} \mathrm{C}$ for $24 \mathrm{hrs}$. 
(Figure 5(D)), indicating the presence of co precipitates of HA and titania as a result of homogeneous precipitation. Pattern showed a very sharp endothermic peak around $100^{\circ} \mathrm{C}$ (characteristic of co precipitation), which was followed by a broad exothermic peak (including a small endothermic bump). The broad peak changed to a plateau shape around $520^{\circ} \mathrm{C}$, and continued until around $800^{\circ} \mathrm{C}$ [41].

iv) Hydroxyapatite, titania (seeded growth (heterogeneous precipitation))

Like phase pure HA (Figure 5(A)), the thermogram of the synthesized material shows three distinct stages of decomposition (Figure $5(\mathrm{G})$ ). The first stage that occurs between $35^{\circ} \mathrm{C}$ and $120^{\circ} \mathrm{C}$ is due to loss of adsorbed water. The major weight loss that occurs between $150^{\circ} \mathrm{C}$ and $260^{\circ} \mathrm{C}$ is assigned to the decomposition of agarose and ammonium. The dehydration of $\mathrm{Ca}(\mathrm{OH})_{2}$ into $\mathrm{CaO}$ also contributes to a part of this weight loss and the total weight loss in this second stage is $9.55 \%$. The third weight loss that occurs between 260 and $380{ }^{\circ} \mathrm{C}$ is due to the decomposition of nitrate. The pattern has very high similarity to standard HA pattern because the amount of dopant (titania) is very small and is in "as precipitated" state. This is also confirmed by XRD pattern of same material and reinforces the hypothesis. DSC analysis (heating) (Figure 5(H)) shows a large broad peak demonstrated by HA powder, which is labelled from around $1200^{\circ} \mathrm{C}$ to $1340^{\circ} \mathrm{C}$ (not shown). It suggests the dehydration of HA over a wide temperature range and phase transformation of HA to oxyhydroxyapatite (OHAP, $\left.\mathrm{Ca}_{10}\left(\mathrm{PO}_{4}\right)_{6}(\mathrm{OH})_{2-\mathrm{x}} \mathrm{O}_{\mathrm{x}}\right)$ as discussed previously for phase pure HA [41] [42]. DSC cooling curves also showed similar pattern as is observed in Figure 5(B) for phase pure HA. Like phase pure HA, only one visible peak is observed, which is around $1440^{\circ} \mathrm{C}$ (not shown), and as discussed previously, it may refer to the reversed full phase transformation from unstable $\bar{\alpha}$-TCP to $\alpha$-TCP [42]. which in turn may have originated from transformation of $\alpha$-TCP at elevated temperatures [42]. Owing to lack of water in the pure nitrogen atmosphere, no peaks referring to reversible transformation from TCP or TTCP to hydroxyapatite or HA are present as was observed previously (Figure 5(B)) [41]. Similarity, Figure 5(B) and Figure $5(\mathrm{H})$ are attributed to same facts and are confirmed by subsequent XRD patterns.

\section{Conclusions}

a) Very fine powders of hydroxyapatite (phase pure), titania (mixture of anatase and rutile), HA, titania (co precipitated (homogeneous reaction)), HA, titania (seeded growth of HA onto titania (heterogeneous reaction)) are formed from novel batch hydrothermal process.

b) XRD patterns along with DSC-TGA scans show successful coprecipitation as well as doping of HA and titania, indicating successful completion of reaction under given condition providing a novel, low temperature quick route to fabricate HA and doped HA materials.

c) Homogeneous precipitation is observed to be a good method for produc- 
tion of doped materials with good process completion, efficiency and phase development.

d) DSC-TGA analysis showed product retained enough properties (in terms of non-transformed phases) to be used for further advanced applications (photocatalysis, drug delivery, and bio marking)

\section{Acknowledgements}

Author would like to thank Aqif A Chaudhry for his helpful guidance, encouragement, support and scientific discussion throughout the work. Author, also like to thank Dr. Adeel Afzal for help in conducting XRD, Ms Sehrish Mukhtar for conducting FTIR and Ms Inum Arshad for conducting TGA Analysis.

\section{References}

[1] Ashok, M., Arivuoli, D., Sundaram, N.M., et al. (2007) Growth and Characterization of Hydroxyapatite Crystals by Hydrothermal Method. Journal of Materials Science: Materials in Medicine, 18, 895-898. https://doi.org/10.1007/s10856-006-0070-5

[2] Chaudhry, A.A., Kellici, S.S., Suela, H., et al. (2006) Instant Nano-Hydroxyapatite: A Continuous and Rapid Hydrothermal Synthesis. Chemical Communications, No. 21, 2286-2288. https://doi.org/10.1039/b518102j

[3] Alby, D., Zajac, J., Prelot, B., et al. (2018) Recent Developments in Nanostructured Inorganic Materials for Sorption of Cesium and Strontium: Synthesis and Shaping, Sorption Capacity, Mechanisms, and Selectivity-A Review. Journal of Hazardous Materials, 344, 511-530. https://doi.org/10.1016/j.jhazmat.2017.10.047

[4] Mohseni-Salehi, M.S., Taheri-Nassaj, E. and Hosseini-Zori, M. (2018) Effect of Dopant (Co, Ni) Concentration and Hydroxyapatite Compositing on Photocatalytic Activity of Titania towards Dye Degradation. Journal of Photochemistry and Photobiology A: Chemistry, 356, 57-70. https://doi.org/10.1016/j.jphotochem.2017.12.027

[5] Prekajski Đorđević, M., Yoshida, K., Babić, B., et al. (2018) In-Situ Immobilization of Sr Radioactive Isotope Using Nanocrystalline Hydroxyapatite. Ceramics International, 44, 1771-1777. https://doi.org/10.1016/j.ceramint.2017.10.110

[6] Stipniece, L., Stepanova, V., et al. (2018) Comparative Study of Surface Properties of Mg-Substituted Hydroxyapatite Bioceramic Microspheres. Journal of the European Ceramic Society, 38, 761-768. https://doi.org/10.1016/j.jeurceramsoc.2017.09.026

[7] Liu, D.-M., Troczynski, T. and Tseng, W.J. (2001) Water-Based Sol-Gel Synthesis of Hydroxyapatite: Process Development. Biomaterials, 22, 1721-1730. https://doi.org/10.1016/S0142-9612(00)00332-X

[8] Arends, J., Christoffersen, J., Eckert, H., et al. (1987) A Calcium Hydroxyapatite Precipitated from an Aqueous Solution: An International Multimethod Analysis. Journal of Crystal Growth, 84, 515-532. https://doi.org/10.1016/0022-0248(87)90284-3

[9] Maity, J.P., Hsu, C.-M., et al. (2018) Removal of Fluoride from Water through Bacterial-Surfactin Mediated Novel Hydroxyapatite Nanoparticle and Its Efficiency Assessment: Adsorption Isotherm, Adsorption Kinetic and Adsorption Thermodynamics. Environmental Nanotechnology, Monitoring and Management, 9, 18-28. 
https://doi.org/10.1016/j.enmm.2017.11.001

[10] Earl, J., Wood, D. and Milne, S. (2006) Hydrothermal Synthesis of Hydroxyapatite. Journal of Physics. Conference Series, 26, 268. https://doi.org/10.1088/1742-6596/26/1/064

[11] Zhang, X. and Vecchio, K.S. (2007) Hydrothermal Synthesis of Hydroxyapatite Rods. Journal of Crystal Growth, 308, 133-140. https://doi.org/10.1016/j.jcrysgro.2007.07.059

[12] Byrappa, K. and Adschiri, T. (2007) Hydrothermal Technology for Nanotechnology. Progress in Crystal Growth and Characterization of Materials, 53, 117-166. https://doi.org/10.1016/j.pcrysgrow.2007.04.001

[13] Byrappa, K. and Yoshimura, M. (2001) Handbook of Hydrothermal Technology: A Technology for Crystal Growth and Materials Processing. Noyes Publications, Norwich, NY.

[14] Khalil, K.M.S. and Zaki, M.I. (1997) Synthesis of High Surface Area Titania Powders via Basic Hydrolysis of Titanium(IV) Isopropoxide. Powder Technology, 92, 233-239. https://doi.org/10.1016/S0032-5910(97)03250-6

[15] Addamo, M., Augugliaro, V., Loddo, V., et al. (2004) Preparation, Characterization, and Photoactivity of Polycrystalline Nanostructured $\mathrm{TiO}_{2}$ Catalysts. The Journal of Physical Chemistry B, 108, 3303-3310. https://doi.org/10.1021/jp0312924

[16] Parra, R., Góes, M.S., Castro, M.S., et al. (2008) Reaction Pathway to the Synthesis of Anatase via the Chemical Modification of Titanium Isopropoxide with Acetic Acid. Chemistry of Materials, 20, 143-150. https://doi.org/10.1021/cm702286e

[17] Mahshid, S., Askari, M. and Ghamsari, M.S. (2007) Synthesis of $\mathrm{TiO}_{2}$ Nanoparticles by Hydrolysis and Peptization of Titanium Isopropoxide Solution. Journal of Materials Processing Technology, 189, 296-300. https://doi.org/10.1016/j.jmatprotec.2007.01.040

[18] Zinfer, R.I., et al. (2009) Synthesis and Stabilization of Nano-Sized Titanium Dioxide. Russian Chemical Reviews, 78, 873. https://doi.org/10.1070/RC2009v078n09ABEH004082

[19] Powder Diffraction Card (PDF Card No. 74-0566). Internatioal Centre for Diffraction Data.

[20] Powder Diffraction Card for Hydroxyapatite (PDF Card No. 9-432). Internatioal Centre for Diffraction Data.

[21] Sadat-Shojai, M. (2009) Preparation of Hydroxyapatite Nanoparticles: Comparison between Hydrothermal and Solvo-Treatment Processes and Colloidal Stability of Produced Nanoparticles in a Dilute Experimental Dental Adhesive. Journal of the Iranian Chemical Society, 6, 386-392. https://doi.org/10.1007/BF03245848

[22] Powder Diffraction Card (PDF Card No. 88-1175, 84-1286). Internatioal Centre for Diffraction Data.

[23] Thamaphat, K., Limsuwan, P. and Ngotawornchai, B. (2008) Phase Characterization of $\mathrm{TiO}_{2}$ Powder by XRD and TEM. Kasetsart Journal-Natural Science, 42, 357-361.

[24] Ninsonti, H., et al. (2009) Hydrothermal Synthesis of Titanium Dioxide $\left(\mathrm{TiO}_{2}\right) \mathrm{Mi}$ cropowder. Journal of Microscopy Society of Thailand, 23, 91-94.

[25] Rafique, M.M.A. (2011) Hydroxyapatite Synthesis and Its Characterization. IRCBM Internal Report (Unpublished).

[26] Tevis, I.D. and Stupp, S.I. (2011) Patterning of Periodic High-Aspect-Ratio Nanopores in Anatase Titanium Dioxide from Titanium Fluoride Hydrolysis. Nanoscale, 3, 2162-2165. https://doi.org/10.1039/c0nr01010c 
[27] Muslimin, M. and Sulaiman, M.Y.M. (2009) In-Situ High Temperature XRD Analysis of Synthesized Calcium Phosphate Biomaterial Using DEHPA as the Starting Material. Journal of Nuclear and Related Technologies, 6, 51-56.

[28] Koutsopoulos, S. (2002) Synthesis and Characterization of Hydroxyapatite Crystals: A Review Study on the Analytical Methods. Journal of Biomedical Materials Research, 62, 600-612. https://doi.org/10.1002/jbm.10280

[29] Stutman, J.M., Termine, J.D. and Posner, A.S. (1965) Vibrational Spectra and Structure of the Phosphate Ion in Some Calcium Phosphates. Transactions of the New York Academy of Sciences, 27, 669-675. https://doi.org/10.1111/j.2164-0947.1965.tb02224.x

[30] Fowler, B.O. (1974) Infrared Studies of Apatites. I. Vibrational Assignments for Calcium, Strontium, and Barium Hydroxyapatites Utilizing Isotopic Substitution. Inorganic Chemistry, 13, 194-207. https://doi.org/10.1021/ic50131a039

[31] Gadaleta, S.J., Mendelsohn, R., Paschalis, E.L., et al. (1995) Fourier Transform Infrared Spectroscopy of Synthetic and Biological Apatites. In: Amjad, Z., Ed., Mineral Scale Formation and Inhibition, Springer, Boston, MA, 283-294.

https://doi.org/10.1007/978-1-4899-1400-2_23

[32] Klee, W.E. and Engel, G. (1970) I.R. Spectra of the Phosphate Ions in Various Apatites. Journal of Inorganic and Nuclear Chemistry, 32, 1837-1843. https://doi.org/10.1016/0022-1902(70)80590-5

[33] Baddiel, C.B. and Berry, E.E. (1966) Spectra Structure Correlations in Hydroxy and Fluorapatite. Spectrochimica Acta, 22, 1407-1416. https://doi.org/10.1016/0371-1951(66)80133-9

[34] Rafique, M.M.A. (2012) Doped Hydroxyapatite Synthesis. IRCBM Internal Report (Unpublished).

[35] Rafique, M.M.A. (2012) Batch Hydrotermal Synthesis of Hydroxyapatite and Metal Oxides. IRCBM Internal Report (Unpublished).

[36] Morterra, C., Bolis, V. and Fisicaro, E. (1989) The Hydrated Layer and the Adsorption of $\mathrm{CO}$ at the Surface of $\mathrm{TiO}_{2}$ (Anatase). Colloids and Surfaces, 41, 177-188. https://doi.org/10.1016/0166-6622(89)80051-4

[37] Barone, J. (1976) A Kinetic Study of the Formation of Calcium Phosphate Minerals. Ph.D. Thesis.

[38] Freund, F. and Knobel, R.M. (1977) Distribution of Fluorine in Hydroxyapatite Studied by Infrared Spectroscopy. Journal of the Chemical Society, Dalton Transactions, No. 11, 1136-1140. https://doi.org/10.1039/dt9770001136

[39] Winand, L., Dallemagne, M.J. and Duyckaerts, G. (1961) Hydrogen Bonding in Apatitic Calcium Phosphates. Nature, 190, 164-165. https://doi.org/10.1038/190164a0

[40] Joris, S.J. and Amberg, C.H. (1971) Nature of Deficiency in Nonstoichiometric Hydroxyapatites. II. Spectroscopic Studies of Calcium and Strontium Hydroxyapatites. The Journal of Physical Chemistry, 75, 3172-3178. https://doi.org/10.1021/j100689a025

[41] Liao, C.-J., Sun, J.-S., et al. (1999) Thermal Decomposition and Reconstitution of Hydroxyapatite in Air Atmosphere. Biomaterials, 20, 1807-1813. https://doi.org/10.1016/S0142-9612(99)00076-9

[42] Li, H., Khor, K.A. and Cheang, P. (2003) Impact Formation and Microstructure Characterization of Thermal Sprayed Hydroxyapatite/Titania Composite Coatings. Biomaterials, 24, 949-957. https://doi.org/10.1016/S0142-9612(02)00431-3 
[43] Sun, H.P., Xu, S.H., et al. (2006) Preparation and Characterization of Visible-Light-Driven Carbon-Sulfur-Codoped $\mathrm{TiO}_{2}$ Photocatalysts. Industrial \& Engineering Chemistry Research, 45, 4971-4976.

https://doi.org/10.1021/ie060350f

[44] Qiu, S. and Kalita, S.J. (2006) Synthesis, Processing and Characterization of Nanocrystalline Titanium Dioxide. Materials Science and Engineering. A, 435-436, 327-332. https://doi.org/10.1016/j.msea.2006.07.062 